\title{
Utilization of Virgin Coconut Meal (VCM) in the Production of Ready-to-Eat Indian Traditional Sweet Meat Using Response Surface Methodology
}

\author{
Yashi Srivastava, Anil Dutt Semwal", Gopal Kumar Sharma, Amarinder Singh Bawa \\ Cereals and Pulses Technology Division, Defence Food Research Laboratory, Siddartha Nagar, Mysore, India. \\ Email: adsemwal@yahoo.co.in
}

Received December 21 $1^{\text {st }}, 2010$; Revised January 12 ${ }^{\text {th }}, 2011$; Accepted March 10 $0^{\text {th }}, 2011$.

\begin{abstract}
Virgin coconut meal (VCM) was used for the development of ready-to-eat Indian traditional sweet meat commonly known as "ladoo" both with and without sorbic acid $(0.3 \%)$. The different ingredients were optimized following response surface methodology with three independent variables i.e. sugar, water and VCM and sensory attributes as responses. The changes in the quality of VCM ladoo packed in polypropylene $(P P, 75 \mu)$ and laminates of metalized polyester $(M P, 75 \mu)$ were monitored during storage to establish the shelf life under ambient temperature conditions $\left(15^{\circ} \mathrm{C}-\right.$ $\left.34^{\circ} \mathrm{C}\right)$. Samples without added potassium sorbate spoiled within three weeks of storage due to mold growth and fermented odour. VCM ladoo containing sorbic acid did not support any microbial growth during storage up to 4 months, however, during storage samples packed in PP lost moisture and became hard and brittle, while those packed in MP remained soft. Peroxide and thiobarbituric acid values were higher in PP packed samples as compared to those packed in MP. Sorbic acid degraded during storage of ladoo and the rate of degradation was higher in PP packed ladoos than that in MP packed ones.
\end{abstract}

Keywords: Virgin Coconut Meal (VCM), Response Surface Methodology, Ladoo, Peroxide Value, Thiobarbituric Acid, Sweet Meat

\section{Introduction}

The top three countries that are in leading position in production of coconut are Indonesia, Philippines and India. In India coconut is cultivated in an area of about 1.78 million hectares. According to FAO 2004 production data the world annual coconut production was 53.00 million tonnes which yielded about 1.80 million tonnes of coconut meal. India's coconut meal production was 0.28 million tonnes which was about 15.4 per cent of world production [1].

Virgin coconut oil (VCO) is the recently emerging highly demanded product in the world and various types of cold and hot presses are used for the extraction of VCO from the fresh coconut kernel at low temperature. The whitish residue remained after extracting coconut oil can be milled to flour named as virgin coconut meal (VCM) [2]. As a source of dietary fiber coconut meal provides a number of health benefits in relation to coronary heart diseases, colon cancer and diabetes $[3,4]$. It has also been reported that consumption of high fiber coconut meal products increases fecal bulk and lowered the serum cholesterol $[5,6]$. In India from long time people always prefer traditional sweets not only on festi- val season but also during common days. The unity in diversity is also comes out in our sweet meat products so it's difficult to predict the origin of any sweet items. Coconut based ladoo is a highly popular Indian sweet and is a rich source of fiber and protein. It is prepared from desiccated coconut powder, sugar or jaggery, wheat flour and hydrogenated fat after adding dry fruits such as cashew nuts, almonds and flavoring substances like cardamom. Because of its moisture content $(12 \%-15 \%)$ and its non acidic nature, spoilage in ladoo is mostly caused by growth of surface yeast and molds, often accompanied by fermentive and acidic odours. Due to their high susceptibility to microbial spoilage, coconut ladoo have very short shelf life. At present coconut ladoo are generally prepared by small scale confectioners and sold loose without any protective packaging. Although some work- 
ers have tried to extend the shelf life of desiccated coconut powder based traditional Indian sweet products viz. Holige, Modaka, Burfi [7-9], no data is available on the composition, method of preparation and packaging requirements of virgin coconut meal (VCM) based ladoo. Since the spoilage in them is largely due to yeasts and molds, studies were undertaken to extend their shelf life under ambient temperature condition $\left(15^{\circ} \mathrm{C}-34^{\circ} \mathrm{C}\right)$ by incorporating sorbic acid, an effective antimycotic agent.

\section{Materials and Methods}

\subsection{Raw Materials}

All the raw materials for making ladoo, which includes whole wheat flour, hydrogenated fat, powdered sugar, cashew nut and desiccated coconut powder were procured from local market, VCM was obtained from Central Plantation Crops Research Institute (CPCRI), Kasaragod, Kerala, India. Analytical grade potassium sorbate was obtained from M/s Loba Chemie Co. Mumbai, India.

\subsection{Preparation of VCM Ladoo}

For the preparation of $2 \mathrm{~kg}$ lot of VCM ladoo, $80 \mathrm{~g}$ whole wheat flour was roasted with $100 \mathrm{~g}$ vanaspati (hydrogenated fat) in an aluminum pan with continuous mixing. The final temperature of the roasts were allowed to rise up to $140^{\circ} \mathrm{C}-150^{\circ} \mathrm{C}$ and desiccated coconut powder $(120$ g) and virgin coconut meal $(230 \mathrm{~g})$ were added and mixed thoroughly. The mixture was again heated till the temperature reached $130^{\circ} \mathrm{C}$ and than allowed to cool to $90^{\circ} \mathrm{C}$ and mixed with powdered sugar $(320 \mathrm{~g})$, fried cashew nut $(20 \mathrm{~g})$ and water $(130 \mathrm{ml})$. This mixture was divided into two lots. Potassium sorbate $(0.4 \%)$ was added to one lot. Both the mixtures were again heated separately till the temperature reached $95^{\circ} \mathrm{C}-98^{\circ} \mathrm{C} .25 \mathrm{~g}$ of this mixture was given round shape by rotating and pressing between palms. One hundred gram samples (4 pieces) were packed in polypropylene (PP, $75 \mu)$ and metallised polyester (MP, 75 $\mu$ ) and heat sealed. The samples were stored under ambient temperature $\left(15^{\circ} \mathrm{C}\right.$ $\left.34^{\circ} \mathrm{C}\right)$ conditions.

\subsection{Experimental Design and Optimization}

Response Surface Methodology (RSM) has been applied for designing and optimization of the experiment following the Central Composite Rota table Design (CCRD). The software used for experimental design and for optimization of ingredients was Design Expert software (Version 8.0.2, Stat ease, Minneapolis, MN, USA).The three coded independent variables i.e. meal $(20 \%-28 \%)$, sugar $(27 \%-37 \%)$ and water $(7 \%-17 \%)$ at 5 levels were mentioned in Table 1. The five sensory responses i.e. colour, aroma, taste, texture and overall acceptability were investigated by 20 semi-trained panellists using 9 point hedonic scale. The data obtained were regressed using multiple regression technique and subsequently, polynomial quadratic regression equations were generated for describing the effect of variables on responses as follows:

$$
Y=\beta_{0}+\sum_{i=1}^{3} \beta_{i} X_{i}+\sum_{i=1}^{3} \beta_{i i} X_{i}^{2}+\sum_{\substack{i, j=1 \\ i \neq j}}^{3} \beta_{i j} X_{i} X_{j}
$$

Response surface plots were generated for describing the effect of variables on responses. Optimization was carried out for the ingredients using same software and keeping the variables in the same range as given in Table $\mathbf{1}$ and maximizing the response values for sensory attributes.

\subsection{Sensory Analysis}

The sensory attributes of the developed VCM ladoo were evaluated in terms of colour, aroma, taste, texture and overall acceptability by a 20 semi-trained panelists on a nine-point hedonic scale with 9 as excellent in all respect and 1 for unacceptable samples [10].

\subsection{Analyses of Ladoo Samples}

Initially and at a regular interval of 1 month, ladoo samples were analyzed for moisture, protein, fat, total ash, sugar and crude fibre contents using Association of official Analytical Chemists methods [11]. Changes in VCM ladoo during storage were monitored by determining peroxide value (PV) and free fatty acid (FFA) as per American Oil Chemist's Society methods [11], while thiobarbituric acid value (TBA) and sorbic acid contents were estimated by the method of Tarladgis et al. 1960 [12] and Thakur et al. 1990 [13] respectively. Fatty acid composition of extracted fat from VCM ladoo was determined by standard AOCS 1990 methods [11] using gas liquid chromatography (Model HR 1000, Chemito, Chennai, India) with $10 \%$ diethylene glycol succinate (DEGS) column. Mineral composition of VCM ladoo

Table 1. Coded and decoded levels of the experimental independent variables used in central composite rotatable design.

\begin{tabular}{cccccccc}
\hline Factor & $\begin{array}{c}\text { Process } \\
\text { variable }\end{array}$ & Units & $\mathbf{- 1}$ & $\mathbf{0}$ & $\mathbf{+ 1}$ & $\mathbf{- 1 . 6 8}$ & $\mathbf{+ 1 . 6 8}$ \\
\hline$X_{1}$ & Meal & $\%$ & 20 & 24 & 28 & 17.27 & 30.72 \\
$X_{2}$ & Sugar & $\%$ & 27 & 32 & 37 & 23.59 & 40.41 \\
$X_{3}$ & Water & $\%$ & 7 & 12 & 17 & 3.59 & 20.40 \\
\hline
\end{tabular}


was determined by atomic absorption spectrophotometer (Model Vario 6 Analytica, Jena, Germany) as per the method of Semwal et al. 1995 [14].

Microbial profile of the VCM ladoo samples were determined using the Petri plate method as described by the American Public Health Association (APHA, 1992) [15] for standard plate count (SPC) on plate count agar, coli form count on violet red bile agar, fecal coli form on Escherichia coli agar and yeast and mold counts on potato dextrose agar. Presence of pathogens viz. coli form, salmonella and staphylococcus aureus was also determined [15].

\subsection{Statistical Analysis}

The data analysis, for Duncan multiple comparisons were done using STATISTICA stat software release 8.0 package.

\section{Results and Discussion}

Sensory evaluation of large number of batches of VCM ladoo prepared from whole wheat flour (WWF), VCM and desiccated coconut powder (DCP) roasted at temperatures ranging from $140^{\circ} \mathrm{C}$ to $150^{\circ} \mathrm{C}$ indicated $145^{\circ} \mathrm{C}$ to be the most optimum. In the present study, powdered sugar was directly added to hydrogenate fat-WWFVCM-DCP mixture as this considerably simplified the up scaling of process. In wet mix process involving sugar syrup, intensive mixing was necessary at elevated temperature and this posed considerable difficulties in the up scaling operations.

The recipe for standardized VCM ladoo was VCM $(23 \%)$, desiccated coconut powder $(12 \%)$, whole wheat flour $(8 \%)$, sugar $(32 \%)$, hydrogenated fat $(10 \%)$, fried cashew nut $(2 \%)$ and water $(13 \%)$. The details of the process conditions optimized for VCM ladoo preparation have been given flow sheet (Figure 1).

The levels of different variables were optimized using RSM. RSM is one of the quite effective in optimizing the ingredient levels in products. Basically RSM helps to create a product using regression equation that describes inter-relations between input parameters and product properties [16]. Earlier some worker has used RSM for optimizing the ingredients in upma mix, a traditional soury product [17] and groundnut burfi [18]. The experiment design, coefficients of polynomial regression model and sum of squares for various responses were given in Tables 1, 2, and 3, respectively.

The sensory score varied from 6.72 to $8.45,6.2$ to 8.65 , 6.91 to $8.72,6.62$ to 8.55 , and 6.51 to 8.69 for color, aroma, taste, texture and overall acceptability, respecttively, in all 20 experimental combinations.

The $\mathrm{R}^{2}$ (Regression coefficient) values were found to

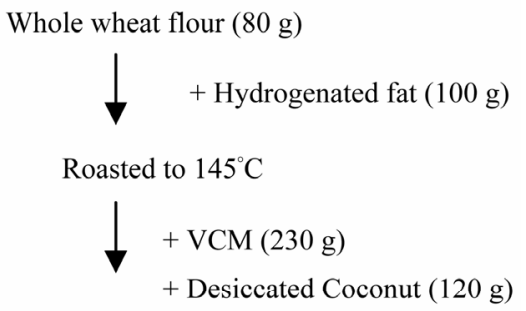

Packed and stored at room temperature

Figure 1. Flow sheet for the preparation of VCM ladoo.

be higher than $85 \%$ for all the responses which indicate fitness of polynomial models used for describing the effect of independent variables on the responses studied. The three variables affected the taste and overall acceptability values significantly $(p \leq 0.05)$ at linear and interactive level, while significant affect on color and texture was observed at $p \leq 0.001$. Whereas, in the case of aroma significant affect was observed at linear $(p \leq 0.01)$ and interactive ( $p \leq 0.001)$ levels. meal and sugar both have negative effect on color, aroma and overall acceptability of VCM ladoo while water has positive effect on all the responses.

The effect of different independent variables on sensory responses could be predicted by following equations:

$$
\begin{aligned}
Y_{\text {Colour }}= & 8.239-0.279 X_{1}-0.055 X_{2}+0.124 X_{3}-0.135 X_{1}^{2} \\
& -0.194 X_{2}^{2}-0.501 X_{3}^{2}-0.09 X_{1} X_{2} \\
& -0.075 X_{1} X_{3}+0.023 X_{2} X_{3} \\
Y_{\text {Aroma }}= & 8.469-0.294 X_{1}-0.048 X_{2}+0.275 X_{3}-0.305 X_{1}^{2} \\
& -0.326 X_{2}^{2}-0.464 X_{3}^{2}-0.05 X_{1} X_{2} \\
& +0.032 X_{1} X_{3}+0.055 X_{2} X_{3} \\
Y_{\text {Taste }}= & 8.633+0.070 X_{1}+0.049 X_{2}+0.157 X_{3}-0.361 X_{1}^{2} \\
& -0.195 X_{2}^{2}-0.464 X_{3}^{2}-0.05 X_{1} X_{2} \\
& -0.062 X_{1} X_{3}+0.055 X_{2} X_{3}
\end{aligned}
$$




$$
\begin{aligned}
Y_{\text {Texture }} & =8.415+0.084 X_{1}-0.169 X_{2}+0.379 X_{3}-0.365 X_{1}^{2} & Y_{O A A}=8.329-0.012 X_{1}-0.098 X_{2}+0.070 X_{3}-0.326 X_{1}^{2} \\
& -0.297 X_{2}^{2}-0.411 X_{3}^{2}-0.005 X_{1} X_{2} & -0.144 X_{2}^{2}-0.208 X_{3}^{2}+0.235 X_{1} X_{2} \\
& +0.04 X_{1} X_{3}+0.062 X_{2} X_{3} & -0.26 X_{1} X_{3}+0.228 X_{2} X_{3}
\end{aligned}
$$

Table 2. Coefficient of second order polynomial regression model for response surfaces fitted to the experimental data points, as a function of three independent variables.

\begin{tabular}{|c|c|c|c|c|c|c|}
\hline \multirow[t]{2}{*}{ Source } & \multirow[t]{2}{*}{ df } & \multicolumn{5}{|c|}{ Sum of Square } \\
\hline & & Color & Aroma & Taste & Texture & OAA \\
\hline Model & 9 & $5.437 * * * *$ & $8.015^{* * *}$ & $5.270^{*}$ & $7.224 * * * *$ & $3.709 *$ \\
\hline \multicolumn{7}{|c|}{ Individual effect of variables } \\
\hline$X_{1}$-Meal $\left(\beta_{1}\right)$ & 1 & $1.067 * * * *$ & $1.184^{* * *}$ & 0.068 & 0.097 & 0.002 \\
\hline$X_{2}$-Sugar $\left(\beta_{2}\right)$ & 1 & $0.042 * *$ & 0.032 & 0.034 & 0.389 & 0.131 \\
\hline$X_{3}$-Water $\left(\beta_{3}\right)$ & 1 & $0.212 * * *$ & $1.035^{*}$ & 0.336 & $1.963 * * * *$ & 0.068 \\
\hline$X_{1} X_{2}\left(\beta_{12}\right)$ & 1 & $0.065^{* *}$ & 0.068 & 0.020 & 0.001 & $0.442 *$ \\
\hline$X_{1} X_{3}\left(\beta_{13}\right)$ & 1 & $0.045 * *$ & 0.008 & 0.031 & 0.013 & $0.541 *$ \\
\hline$X_{2} X_{3}\left(\beta_{23}\right)$ & 1 & 0.004 & 0.007 & 0.024 & 0.031 & $0.414 *$ \\
\hline$X_{1}^{2} \quad\left(\beta_{11}\right)$ & 1 & $0.265 * * *$ & $1.342 * *$ & $1.880^{*}$ & $1.923 * * * *$ & $1.532 * * *$ \\
\hline$X_{2}^{2} \quad\left(\beta_{22}\right)$ & 1 & $0.541 * * * *$ & $1.535^{* * *}$ & $0.548^{*}$ & $1.279^{* * *}$ & $0.298^{*}$ \\
\hline$X_{3}^{2}\left(\beta_{33}\right)$ & 1 & $3.623 * * * *$ & $3.804 * * * *$ & $3.099 * * *$ & $2.436^{* * * *}$ & $0.621 *$ \\
\hline \multicolumn{7}{|c|}{ Combined effect of variables } \\
\hline Linear & 11 & $4.179 * * * *$ & $6.298 * *$ & $5.640^{*}$ & $5.081 * * *$ & $3.878^{*}$ \\
\hline Interactive & 8 & $4.065 * * * *$ & $6.214^{* * *}$ & $5.565^{*}$ & $5.037 * * *$ & $2.481 *$ \\
\hline Quadratic & 5 & 0.063 & 0.535 & 0.807 & 0.308 & 0.369 \\
\hline
\end{tabular}

\begin{tabular}{cccccc}
\hline Coefficient & Color & Aroma & Taste & Texture & OAA \\
\hline Intercept $\left(\beta_{0}\right)$ & 8.239 & 8.469 & 8.633 & 8.415 & 8.329 \\
$X_{1}$-Meal $\left(\beta_{1}\right)$ & -0.279 & -0.294 & 0.070 & 0.084 & -0.012 \\
$X_{2}$-Sugar $\left(\beta_{2}\right)$ & -0.055 & -0.048 & 0.049 & -0.169 & -0.098 \\
$X_{3}$-Water $\left(\beta_{3}\right)$ & 0.124 & 0.275 & 0.157 & 0.379 & 0.070 \\
$X_{1} X_{2}\left(\beta_{12}\right)$ & -0.09 & -0.092 & -0.05 & -0.005 & 0.235 \\
$X_{1} X_{3}\left(\beta_{13}\right)$ & -0.075 & 0.032 & -0.062 & 0.04 & -0.26 \\
$X_{2} X_{3}\left(\beta_{23}\right)$ & 0.023 & 0.03 & 0.055 & 0.062 & 0.228 \\
$X_{1}^{2}\left(\beta_{11}\right)$ & -0.135 & -0.305 & -0.361 & -0.365 & -0.326 \\
$X_{2}^{2}\left(\beta_{22}\right)$ & -0.194 & -0.32 & -0.195 & -0.297 & -0.144 \\
$X_{3}^{2}\left(\beta_{33}\right)$ & -0.501 & -0.514 & -0.464 & -0.411 & -0.208 \\
$R^{2}(\%)$ & 99.25 & 92.45 & 84.15 & 95.35 & 88.28 \\
\hline
\end{tabular}

Table 3. Sum of squares of sensory responses according to response surface methodology.

${ }^{*} p \leq 0.05,{ }^{* *} p \leq 0.01,{ }^{* * *} p \leq 0.001,{ }^{* * * *} p \leq 0.0001$. 
The effect of meal and sugar (Figure 2) showed that the OAA was increased with the increased in concentration of meal and sugar up to a certain level and then declined. The effects of water and sugar as well as water and meal level, also followed a similar trend (Figures 3 and 4).

The optimized conditions for independent variables were obtained at $23 \%$ for meal, $32 \%$ for sugar and $13 \%$ for water. The predicted and actual values of responses at optimized conditions showed good correlation. The optimized VCM ladoo had $12.26 \%$ moisture, $30.34 \%$ fat, $5.23 \%$ protein, $33.1 \%$ total sugar, and $5.26 \%$ crude fibre,

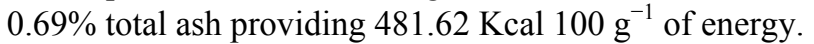

The fatty acid profile of the fat extracted from VCM ladoo and mineral composition are given in Table 4.

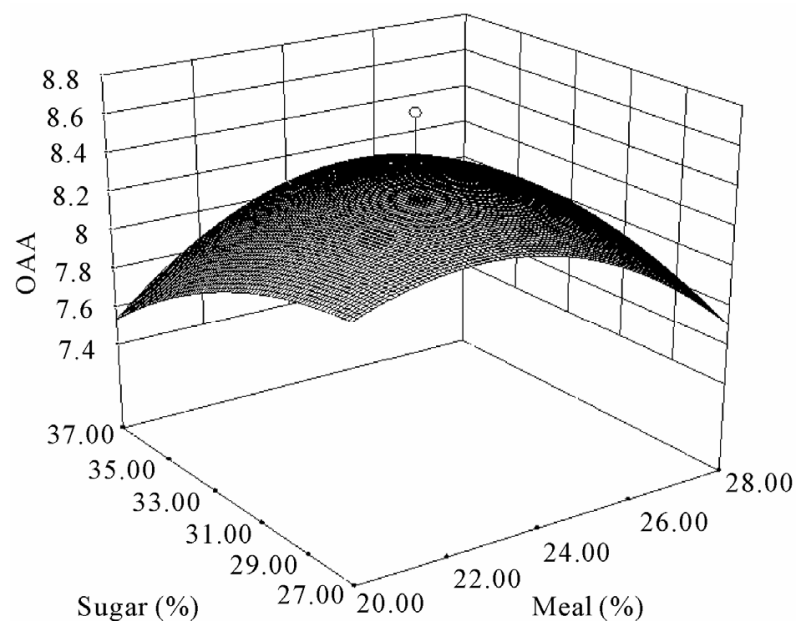

Figure 2. Effect of levels of meal and sugar on overall acceptability of the VCM ladoo.

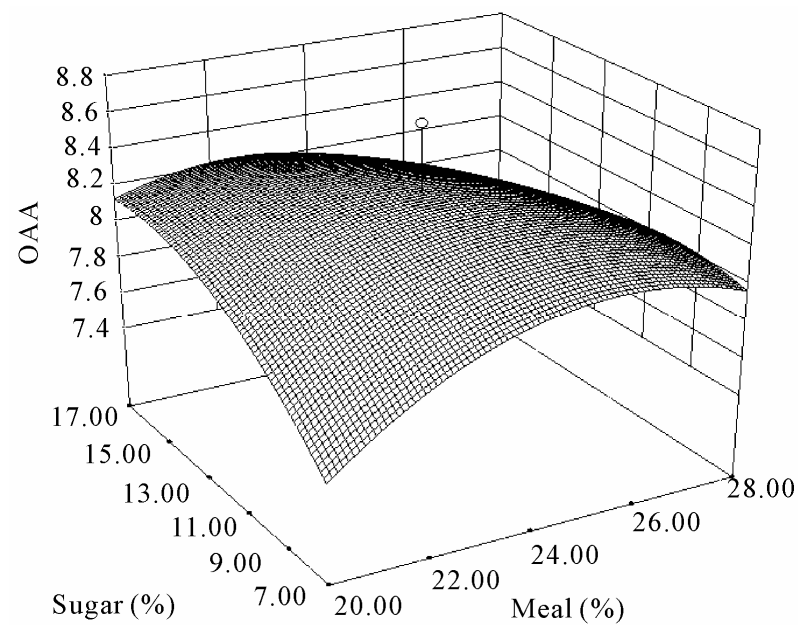

Figure 3. Effect of levels of meal and water on overall acceptability of the VCM ladoo.

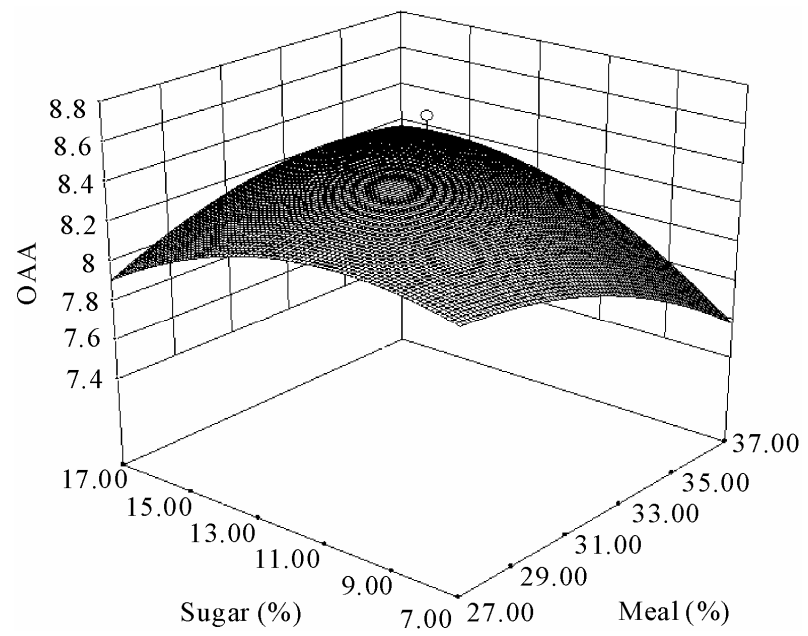

Figure 4. Effect of sugar and water on overall acceptability of the VCM ladoo.

Table 4. Fatty acid* (\%) and mineral composition* (mg/ 100g) of optimized VCM ladoo.

\begin{tabular}{cc}
\hline Caproic & $0.09 \pm 0.002$ \\
Capric & $5.70 \pm 0.04$ \\
Capryllic & $4.37 \pm 0.02$ \\
Lauric & $35.06 \pm 0.04$ \\
Myristic & $13.57 \pm 0.02$ \\
Palmitic & $21.76 \pm 0.02$ \\
Oleic & $19.45 \pm 0.03$ \\
Calcium & $22.18 \pm 1.10$ \\
Zinc & $0.92 \pm 0.07$ \\
Iron & $6.06 \pm 0.28$ \\
Sodium & $81.25 \pm 1.85$ \\
Potassium & $467.68 \pm 2.50$ \\
\hline
\end{tabular}

*Mean $( \pm \mathrm{SD}, n=3)$.

Lauric acid (35.08\%) was the major fatty acid present followed by palmitic $(21.76 \%)$, oleic acid $(19.45 \%)$. The concentration of potassium $\left(467.68 \mathrm{mg} 100 \mathrm{~g}^{-1}\right)$ in $\mathrm{VCM}$ ladoo was high and this may be attributed to a high level of potassium in coconut meal [19].

VCM ladoo prepared without incorporating potassium sorbate developed mold growth and fermented odour within 20 days of storage in both the packaging materials. Total yeasts, mold and bacterial counts increased considerably $\left(>10^{4} \mathrm{cfu} \cdot \mathrm{g}^{-1}\right)$ and further storage was discontinued. However, ladoo samples incorporated with potassium sorbate did not support mold growth and fer- 
mented odour and remained stable and acceptable up to 3 and 4 months in PP and MP films, respectively. Earlier, Satyanarayan Rao et al. [7,8] also attempted to enhance the shelf life of coconut based traditional Indian sweet meats such as Holige (sweet stuffed chapatti), Modaka and burfi by incorporating $0.2 \%$ sorbic acid and packing them in PP $(75 \mu)$ and paper (42GSM)-aluminium foil $(0.02 \mathrm{~mm})$-polyethylene $(37.5 \mu)$ laminate pouches (PFP) up to 6 months at ambient temperatures. Gupta et al. 2010 attempted in-pack heat processing for extending the shelf life of coconut burfi in flexible pouches of multilayer film up to 75 days at $27^{\circ} \mathrm{C}$ [9].

The data on microbiological profile of the VCM ladoo samples shown that the yeast and mold counts in sorbic acid treated samples were less than $20 \mathrm{cfu} \cdot \mathrm{g}^{-1}$ during the storage. SPCs in sorbic acid treated samples were also less than $150 \mathrm{cfu} \cdot \mathrm{g}^{-1}$ and no coli form and fecal coli form were found in the stored ladoo samples up to 120 days.

The pathogens viz. E. coli, S. aureus and salmonella were also absent in all the stored samples. Table 5 shows the physico-chemical changes for sorbate added VCM ladoo packed in different packaging materials and stored under ambient temperature conditions. As can be seen, moisture in PP packed samples decreased considerably whereas in MP packed samples, there was negligible loss.

Due to this excessive moisture loss, samples packed in PP films became hard. Relatively, higher losses in moisture in ladoos packed in PP films are expected due to their high water vapour transmission rates $\left(10.8 / \mathrm{m}^{2} / 24\right.$ $\mathrm{h} / 37^{\circ} \mathrm{C} / 95 \% \mathrm{RH}$ ). The changes in free fatty acids (Table 5) seemed to be governed by the moisture content of the stored samples. Increase in FFA was higher in sample stored in MP than in PP stored ones.

After 4 months of storage, PV and TBA values for VCM ladoos increased from 5.32 and 0.09 to 23.82, 13.28 meq $\mathrm{O}_{2} \mathrm{~kg}^{-1}$ and $0.32,0.21 \mathrm{mg} \mathrm{MA} \mathrm{kg}^{-1}$ for PP and MP packed samples, respectively.

In packed products, the rate of lipid autoxidation is mainly governed by the oxygen retention in the pack, which in turn is related to the headspace and oxygen permeability of the packaging material. The oxygen permeability of PP being higher than of MP film resulted in greater increase in peroxide and TBA values in sample packed in PP, as expected.

Changes in color, taste, aroma, texture and overall acceptability of VCM ladoo samples stored at ambient temperatures in PP and MP films are given in Table 5. Initially, VCM ladoo had an overall acceptability score of 8.17 on a 9-point hedonic scale and therefore a score of 7.0 was taken as limit of shelf life in storage experiments.

Based on this criterion, the VCM ladoo remained acceptable for 3 and 4 months under ambient temperature conditions when packed in PP and MP respectively. The concentration of sorbic acid gradually decreased during storage of VCM ladoo (Table 6).

The losses were higher for PP packed sample (30.76\%) as compared with those for MP-packed one (17.48\%) after 4 months of storage. The rate of autoxidative degradation of sorbic acid in VCM ladoo was considerably lower than that reported in fruit squash, fish paste and aqueous solutions (Arya, 1980; Vidyasagar and Arya, 1984). A number of factors, like higher sugar level (33\%),

Table 5. Changes in physico-chemical and sensory parameters of potassium sorbate preserved VCM ladoo packed in PP and MP pouches and stored under ambient temperature $\left(15^{\circ} \mathrm{C}-34^{\circ} \mathrm{C}\right)$ conditions.

\begin{tabular}{|c|c|c|c|c|c|c|c|c|c|}
\hline \multirow[t]{2}{*}{ Parameter } & \multirow[t]{2}{*}{ Initial } & \multicolumn{2}{|c|}{1 Month } & \multicolumn{2}{|c|}{2 Month } & \multicolumn{2}{|c|}{3 Month } & \multicolumn{2}{|c|}{4 Month } \\
\hline & & PP & MP & PP & MP & PP & MP & PP & MP \\
\hline Moisture & $12.26^{\mathrm{a}}$ & $11.89^{\mathrm{a}}$ & $12.02^{\mathrm{a}}$ & $10.78^{b}$ & $11.96^{\mathrm{a}}$ & $9.59^{\mathrm{c}}$ & $11.61^{\mathrm{a}}$ & $8.42^{\mathrm{d}}$ & $11.09^{\mathrm{a}}$ \\
\hline PV & $5.32^{\mathrm{a}}$ & $7.36^{\mathrm{b}}$ & $6.34^{\mathrm{c}}$ & $9.12^{\mathrm{d}}$ & $7.12^{\mathrm{b}}$ & $16.15^{\mathrm{e}}$ & $10.09^{\mathrm{f}}$ & $23.82^{\mathrm{g}}$ & $13.28^{\mathrm{h}}$ \\
\hline FFA & $0.57^{\mathrm{a}}$ & $1.08^{\mathrm{b}}$ & $1.10^{\mathrm{b}}$ & $1.62^{\mathrm{c}}$ & $1.83^{\mathrm{cd}}$ & $2.13^{\mathrm{de}}$ & $2.38^{\mathrm{e}}$ & $2.56^{\mathrm{ef}}$ & $2.82^{\mathrm{f}}$ \\
\hline TBA & $0.09^{\mathrm{a}}$ & $0.10^{\mathrm{a}}$ & $0.10^{\mathrm{a}}$ & $0.15^{\mathrm{b}}$ & $0.13^{\mathrm{b}}$ & $0.21^{\mathrm{c}}$ & $0.16^{\mathrm{b}}$ & $0.32^{\mathrm{d}}$ & $0.21^{\mathrm{c}}$ \\
\hline Color & $8.25^{\mathrm{a}}$ & $7.83^{\mathrm{b}}$ & $7.91^{\mathrm{b}}$ & $7.48^{\mathrm{c}}$ & $7.74^{\mathrm{b}}$ & $7.01^{\mathrm{d}}$ & $7.46^{\mathrm{c}}$ & $6.42^{\mathrm{e}}$ & $7.11^{\mathrm{f}}$ \\
\hline Aroma & $8.11^{\mathrm{a}}$ & $7.95^{\mathrm{a}}$ & $7.97^{\mathrm{a}}$ & $7.52^{\mathrm{b}}$ & $7.83^{\mathrm{ab}}$ & $7.12^{\mathrm{c}}$ & $7.55^{\mathrm{b}}$ & $6.48^{\mathrm{d}}$ & $7.18^{\mathrm{c}}$ \\
\hline Taste & $8.13^{\mathrm{a}}$ & $7.89^{\mathrm{a}}$ & $7.94^{\mathrm{a}}$ & $7.56^{\mathrm{b}}$ & $7.78^{\mathrm{b}}$ & $7.04^{\mathrm{c}}$ & $7.49^{\mathrm{bc}}$ & $6.63^{\mathrm{d}}$ & $7.21^{\mathrm{c}}$ \\
\hline Texture & $8.16^{\mathrm{a}}$ & $7.72^{\text {bcd }}$ & $7.82^{\text {bd }}$ & $7.46^{\mathrm{cd}}$ & $7.69^{d}$ & $7.16^{\mathrm{e}}$ & $7.39^{\mathrm{e}}$ & $6.18^{\mathrm{f}}$ & $7.16^{\mathrm{e}}$ \\
\hline OAA & $8.17^{\mathrm{a}}$ & $7.67^{\mathrm{b}}$ & $7.99^{\mathrm{a}}$ & $7.50^{\mathrm{b}}$ & $7.72^{\mathrm{b}}$ & $7.10^{\mathrm{c}}$ & $7.45^{\mathrm{b}}$ & $6.28^{\mathrm{d}}$ & $7.12^{\mathrm{c}}$ \\
\hline
\end{tabular}

Values in same row with different letters differ significantly $(p \geq 0.05), n=3$. 
Table 6. Changes in the concentration of sorbic acid $(\%)$ in VCM ladoo packed in PP and MP and stored under ambient temperature $\left(15^{\circ} \mathrm{C}-34^{\circ} \mathrm{C}\right)$ conditions.

\begin{tabular}{ccc}
\hline Storage period & PP & MP \\
\hline Initial & $0.286 \pm 0.002^{\mathrm{a}}$ & $0.286 \pm 0.002^{\mathrm{a}}$ \\
& $0.280 \pm 0.002^{\mathrm{a}}$ & $0.282 \pm 0.002^{\mathrm{a}}$ \\
1 Month & $(2.09 \%)^{+}$ & $(1.39 \%)$ \\
& $0.271 \pm 0.002^{\mathrm{b}}$ & $0.276 \pm 0.002^{\mathrm{b}}$ \\
\multirow{2}{*}{ Month } & $(5.24 \%)$ & $(3.49 \%)$ \\
& $0.238 \pm 0.003^{\mathrm{c}}$ & $0.258 \pm 0.002^{\mathrm{cx}}$ \\
3 Month & $(16.78 \%)$ & $(9.79 \%)$ \\
& $0.198 \pm 0.004^{\mathrm{d}}$ & $0.236 \pm 0.004^{\mathrm{dx}}$ \\
4 Month & $(30.76 \%)$ & $(17.48 \%)$ \\
\hline
\end{tabular}

*Mean $\pm \mathrm{SD} ;{ }^{+}$Figure in parenthesis indicates percentage loss; Values in same column with different letters differ significantly $(p \leq 0.05) ; x$ Significantly different from their corresponding PP samples $(p \leq 0.05), n=3$.

high $\mathrm{pH}$ (6.81) and solid matrix, may be responsible for the lower degradation of sorbic acid in VCM ladoo.

\section{Conclusions}

Since no rancid odors became perceptible during storage of VCM ladoo up to 4 months under ambient temperature conditions, the autoxidation of lipids does not seem to be the main factor in determining its shelf life. Besides microbiological spoilage, hardening of texture seemed to exert greater influence on the sensory acceptance of the VCM ladoo. Therefore, packaging materials having intermediate water vapour transmission rates, low oxygen permeability would be more desirable in combination with antimycotic agents for ensuring maximum shelf life of the product.

\section{Acknowledgement}

The authors are grateful to National Agricultural Innovation Project (NAIP) and Director, Central Plantation Crops Research Institute (CPCRI), Kasargod, Kerala for providing the $\mathrm{VCM}$ required for the study.

\section{REFERENCES}

[1] M. Moorthy and K. Viswanathan, "Nutritive Value of Extracted Coconut (Cocos Nucifera) Meal," Research Journal of Agriculture and Biological Science, Vol. 5, No. 4, 2009, pp. 515-517.

[2] D. D. Bawalan, "The Economics of Production, Utilization and Marketing of Coconut Flour from Coconut Milk Residue," Center for Occupational Research and Development, Vol. 16, No. 1, 2000, pp. 1-13.

[3] K. D. P. P. Gunathilake and Y. M. R. K. Abeyrathne, "Incorporation of Coconut Flour into Wheat Flour Noodles and Evaluation of Its Rheological, Nutritional and Sensory Characteristics," Journal of Food Processing and
Preservation, Vol. 32, No. 1, 2008, pp. 133-142. doi:10.1046/j.1439-0361.2003.02062.x

[4] T. P. Trinidad, D. H. Valdez, A. S. Loyola, A. C Mallillin, F. C. Askali, J. C. Castillo and D. B. Masa, "Glycemic Index of Different Coconut (Cocos Nucifera) Flour Products in Normal and Diabetic Subjects," British Journal of Nutrition, Vol. 90, No. 3, 2007, pp. 551-556. doi:10.1079/BJN2003944

[5] K. D. P. P. Gunathilake, C. Yalegana and A. A. N. Kumara, "Use of Coconut Flour as a Source of Protein and Dietary Fiber in Wheat Bread," Asian Journal of Food and Agro-Industry, Vol. 2, No. 3, 2009, pp. 382-391.

[6] R. N. Arancon, "Coconut Flour," Cocoinfo International, Vol. 6, No. 1, 1999, pp. 8-10.

[7] T. S. Satyanarayan Rao, N. M. Kaverappa and K. S. Jayarawan, "Development of Shelf Stable Ready-to-Eat Indian Sweet Meats Based on Sugar and Coconut," Journal of Food Science Technology, Vol. 27, No. 6, 1990, pp. 359-361.

[8] T. S. S. Rao, N. M. Kaverappa, R. Hemaprakash and K. S. Jayarawan, "Development of Ready-to-Eat Traditional Indian Sweet Dishes Based on Jaggery and Coconut," Journal of Food Science Technology, Vol. 27, No. 5, 1990, pp. 355-358.

[9] V. Gupta, N. S. Vijaylakshmi, B. Ashwini, K. Anbarash, G. Vijaylakshmi, P. Maya, A. R. Indiramma, G. C. P. Rangarao and B. S. Ramesh, "Shelf Life Enhancement of Coconut Burfi-An Indian Traditional Sweet," Journal of Food Quality, Vol. 33, No. 3, 2010, pp. 329-349. doi:10.1111/j.1745-4557.2010.00312.x

[10] E. Larmond, "Laboratory Methods for Sensory Evaluation of Foods," Canada Department of Agriculture Publication, Ottawa, 1977.

[11] Association of Official Analytical Chemists, "AOAC Official Methods of Analysis," 15th Edition, Washington DC, 1990.

[12] B. G. Tarladgis, B. M. Watts, M. T. Younathan and L. J. Dugan, "A Distillation Method for the Qualitative Determination of Malonaldehyde in Rancid Food," Journal of American Oil Chemists' Society, Vol. 37, No. 1, 1960, pp. 44-47.

[13] B. R. Thakur, J. R. Threhan and S. S Arya, "Radiolytic Degradation of Sorbic Acid in Isolated Systems," Journal of Food Science, Vol. 55, No. 6, 1990, pp. 1699-1702. doi:10.1111/j.1365-2621.1990.tb03604.x

[14] A. D. Semwal, M. C. N. Murthy and S. S. Arya, "Metal Contents in Some of the Processed Foods and Their Effect on the Storage Stability of Precooked Dehydrated Flaked Bengal Gram Dhal," Journal of Food Science Technology, Vol. 32, No. 5, 1995, pp. 386-390.

[15] American Public Health Association, "Compendium of Methods for the Microbiological Examination of Food," 2nd Edition, American Public Health Association, Washington DC, 1992.

[16] P. Colona, J. L. Doublier, J. P. Meleion, F. D. Monfredon and C. Mereier, "Extrusion Cooking and Drum Drying of 
Wheat Starch, I, Physical and Macromolecular Modifications," Cereal Chemistry, Vol. 61, 1984, pp. 538-543.

[17] D. N. Yadav and G. K. Sharma, "Optimization of Soyfortified Instant Upma Mix Ingredients Using Response Surface Methodology," Journal of Food Science Technology, Vol. 45, No. 1, 2008, pp. 56-60.

[18] M. A. Khan, A. D. Semwal, G. K. Sharma, D. N. Yadav and K. A. Srihari, "Studies on the Development and Storage Stability of Groundnut (Arachis Hypogea) Burfi," Journal of Food Quality, Vol. 31, No. 5, 2008, pp. 612-626. doi:10.1111/j.1745-4557.2008.00224.x

[19] C. Gopalan, B. V. R. Shastri and S. C. Balasubramanian, "Nutritive Value of Indian Foods," National Institute of Nutrition, Hyderabad, 1985. 